\title{
Fabrication of porous carbon monoliths with a graphitic framework
}

\author{
Marta Sevilla and Antonio B. Fuertes ${ }^{1}$ \\ Instituto Nacional del Carbón (CSIC), P. O. Box 73, 33080-Oviedo, Spain
}

\begin{abstract}
Macro/mesoporous carbon monoliths with a graphitic framework were synthesized by carbonizing polymeric monoliths of poly(benzoxazine-co-resol). The overall synthesis process consists of the following steps: a) the preparation of polymeric monoliths by copolymerization of resorcinol and formaldehyde with a polyamine (tetraethylenepentamine), b) doping the polymer with a metallic salt of $\mathrm{Fe}, \mathrm{Ni}$ or $\mathrm{Co}, \mathrm{c}$ ) carbonization and d) the removal of inorganic nanoparticles. The metal nanoparticles ( $\mathrm{Fe}, \mathrm{Ni}$ or $\mathrm{Co}$ ) formed during the carbonization step catalyse the conversion of a fraction of amorphous carbon into graphitic domains. The resulting carbon monoliths contain $>$ $50 \mathrm{wt} \%$ of graphitic carbon, which considerably improves their electrical conductivity. The use of tetraethylenepentamine in the synthesis results in a nitrogen-containing framework. Textural characterization of these materials shows that they have a dual porosity made up of macropores and mesopores $(\sim 2-10 \mathrm{~nm})$, with a BET surface area in the $280-400 \mathrm{~m}^{2} \cdot \mathrm{g}^{-1}$ range. We tested these materials as electrodes in organic electrolyte supercapacitors and found that no conductive additive is needed due to their high electrical conductivity. In addition, they show a specific capacitance of up to $35 \mathrm{~F} \cdot \mathrm{g}^{-1}$, excellent rate and cycling performance, delivering up to $10 \mathrm{~kW} \mathrm{~kg}^{-1}$ at high current densities.
\end{abstract}

\footnotetext{
* Corresponding author. E-mail address: abefu@incar.csic.es (A.B. Fuertes)
} 


\section{Introduction}

The design and fabrication of porous carbons with appropriate structural and chemical properties has recently generated a great deal of interest because of their applicability in numerous fields such as: (i) the storage of electrical energy in supercapacitors [1], (ii) the immobilization and separation of large biomolecules [2], (iii) $\mathrm{CO}_{2}$ capture [3], (iii) hydrogen storage [4], (iv) the adsorption of specific contaminants in liquid phase (e.g. dyes, heavy metal ions, anions, etc.) [5], (v) catalytic supports in fuel cells [6], etc. To enhance the performance of porous carbons for each individual case, it is important that the properties of the material match the requirements of the application. In this regard, these materials normally consist of a powder made up of fine carbon particles. However, some types of structure such as highly permeable monolithic porous carbons, may be more useful in applications related to electrochemistry or separation processes (e.g. chromatographic columns, filtration devices, etc) owing to their easy manageability, low pressure drop, improved electron conductivity and electrolyte diffusion [7-10]. Two synthesis strategies for fabricating carbon monoliths have so far been reported. One is the nanocasting approach, which requires multiple steps and the use of templates, normally porous polymer or silica monoliths [11-13]. Due to the complexity of the nanocasting route, other easier alternatives which circumvent the need for sacrificial templates, have been recently examined. One such alternative is the production of carbons with a monolithic structure by simple carbonization of polymeric porous monoliths. Research groups who have used this method include Liang and Dai who prepared bimodal porous carbon monoliths by means of a dual phase separation process using phloroglucinol/formaldehyde copolymer as carbon precursor [14], Huang et al. who reported the fabrication of carbonaceous monoliths using phenolic resols as precursors via a one-step hydrothermal 
approach [15], and Hao et al. who prepared porous carbon monoliths with a nitrogencontaining framework and a high mechanical strength through self-assembly of poly(benzoxazine-co-resol) followed by a carbonization process [16].

In contrast to carbon powders, carbon monoliths exhibit a high permeability and interconnectivity, two features that ensures high mass transfer rates and a good electronic conductivity, a property that is essential in electrochemical applications such as energy storage (i.e. supercapacitors or lithium-ion batteries) and for use as electrocatalytic supports in fuel cells. However, carbon monoliths usually have amorphous carbon frameworks with poor electronic conductivity, a drawback that limits their applicability in electrochemical systems. A simple way to overcome this problem is to fabricate porous carbon monoliths that contain graphitic domains within their framework. For example, Liang et al. reported the fabrication of graphitic carbon monoliths by means of a nanocasting route using silica nanospheres as sacrificial template, resorcinol-formaldehyde (RF) as carbon precursor and iron (III) as graphitization agent [17]. The resulting carbon monolith exhibits a macrocellular structure specially designed for use as a chromatographic column. However, fabrication of this material requires a sacrificial template (i. e. silica nanospheres) with the added disadvantage that its pore development is poor $\left(\mathrm{S}_{\mathrm{BET}}<200 \mathrm{~m}^{2} \cdot \mathrm{g}^{-1}\right)$. The challenge then is to develop a simple synthesis strategy for making porous carbon monoliths that combine a high and accessible pore development with graphitic domains that provide a good electronic conductivity.

This study presents a controllable and facile method to synthesize mesoporous graphitic carbon monoliths, which combine high surface areas, large pore volumes formed by accessible mesopores and good electronic conductivities. These monoliths were prepared without the aid of any sacrificial hard templates by using as carbon 
precursor a porous polymer (i.e. poly(benzoxazine-co-resol)), synthesized following a procedure recently described by Hao et al. [16]. In order to generate graphitic domains in the carbon monolith, the polymeric precursor was impregnated with various metal compounds that give rise to metallic nanoparticles which act as catalysts for the conversion of amorphous carbon into graphitic domains. This process occurs at relatively low carbonization temperatures $\left(<1000{ }^{\circ} \mathrm{C}\right)$. The resultant carbonaceous monoliths contain more than $50 \%$ of graphitic carbon and they exhibit a good electronic conductivity. In this paper, the performance of this material as electrodes in supercapacitors is assessed.

\section{Experimental section}

\subsection{Chemicals}

Triblock copolymer Pluronic P127 ( $M w=12600$, PEO106PPO70PEO106), resorcinol (99 wt \%), formalin (37 wt \% formaldehyde in water), $\mathrm{Fe}\left(\mathrm{NO}_{3}\right)_{3} .9 \mathrm{H}_{2} \mathrm{O}$ (97 wt \%), $\mathrm{Co}\left(\mathrm{NO}_{3}\right)_{2} \cdot 6 \mathrm{H}_{2} \mathrm{O}(98 \mathrm{wt} \%), \mathrm{Ni}\left(\mathrm{NO}_{3}\right)_{2} \cdot 6 \mathrm{H}_{2} \mathrm{O}(98 \mathrm{wt} \%)$, tetraethylenepentamine (denoted TEPA, 97 wt \%) were supplied by Sigma-Aldrich. Ethanol (99 \%) and hydrochloric acid (37 wt \%) were purchased from Panreac. Deionized water was used in all the experiments.

\subsection{Synthesis of graphitic carbon monoliths}

A typical synthesis of undoped monolithic polymer precursor involved the following steps. $0.42 \mathrm{~g}(0.033 \mathrm{mmol})$ of Pluronic F-127 and $1 \mathrm{~g}(9.1 \mathrm{mmol})$ of resorcinol were dissolved in a solvent mixture of water $(3 \mathrm{~mL})$ and ethanol $(3.8 \mathrm{~mL})$ under magnetic stirring at room temperature. After that, $0.06 \mathrm{~g}(0.3 \mathrm{mmol})$ of polyamine TEPA was added to the above solution and stirred for $30 \mathrm{~min}$ at room temperature. Subsequently, $1.5 \mathrm{~mL}$ (18.5 mmol formaldehyde) of formalin was injected into the solution. The 
reaction mixture was stirred for five minutes. The solution was then poured into a Teflon autoclave which was placed in an oven at $100^{\circ} \mathrm{C}$ and left for $4 \mathrm{~h}$. The resulting polymeric monolith was dried at $50{ }^{\circ} \mathrm{C}$ for $24 \mathrm{~h}$. The as-made polymeric monoliths were heat-treated under a flow of nitrogen at $350{ }^{\circ} \mathrm{C}\left(2 \mathrm{~h}, 5^{\circ} \mathrm{C} \cdot \mathrm{min}^{-1}\right)$ in order to remove the F-127 surfactant. This sample (denoted as CRF-350) was used for the fabrication of graphitic monoliths. A non-graphitic carbon monolith (denoted as CRF-800) was prepared by means of carbonization of a polymeric sample under a flow of nitrogen at $800{ }^{\circ} \mathrm{C}\left(1 \mathrm{~h}, 5^{\circ} \mathrm{C} \cdot \mathrm{min}^{-1}\right)$.

To promote the graphitization of the carbon monoliths, the following procedure was adopted. The CRF-350 monolith was impregnated dropwise with a solution of metal (Fe, Ni or $\mathrm{Co})$ nitrate in ethanol up to incipient wetness $(\sim 5 \mathrm{mmol}$ of metal nitrate per gram of CRF-350). The impregnated sample was then dried under vacuum at $55{ }^{\circ} \mathrm{C}$ for $6 \mathrm{~h}$ and heat-treated under a nitrogen flow up to a temperature in the $800-1000{ }^{\circ} \mathrm{C}$ range for $1 \mathrm{~h}$ (Heating rate: $\left.5{ }^{\circ} \mathrm{C} \cdot \mathrm{min}^{-1}\right)$. Finally, the carbonized monolith was treated with concentrated hydrochloric acid to remove the metal nanoparticles, washed with abundant deionized water and dried at $120^{\circ} \mathrm{C}$ for several hours. The porous graphitic monoliths prepared in this way were denoted as $P G M-X-Y, X$ being the metal used as graphitization catalyst and $Y$ the carbonization temperature in ${ }^{\circ} \mathrm{C}$.

An alternative more direct synthesis route for synthesizing porous graphitic carbon monoliths was also employed. This involved using a Co-doped polymer monolith as carbon precursor. The synthesis procedure in this case was similar to that previously described except that $1.17 \mathrm{~g}(4 \mathrm{mmol})$ of $\mathrm{Co}\left(\mathrm{NO}_{3}\right)_{2} \cdot 6 \mathrm{H}_{2} \mathrm{O}$ was added to the reaction mixture after the surfactant (Pluronic F-127) had dissolved. The resulting Codoped polymeric monolith was dried at $50{ }^{\circ} \mathrm{C}$ for $24 \mathrm{~h}$ and then heat-treated under nitrogen up to $800{ }^{\circ} \mathrm{C}$ for $1 \mathrm{~h}$ (Heating rate: $5{ }^{\circ} \mathrm{C} \cdot \mathrm{min}^{-1}$ ). The resulting Co-doped carbon 
monolith was treated with concentrated hydrochloric acid to remove the cobalt nanoparticles, washed with abundant deionized water and dried a $120{ }^{\circ} \mathrm{C}$ for several hours. This porous graphitic monolith was denoted as PGM-Co-D-800.

\subsection{Characterization}

Low-angle range X-ray diffraction (XRD) patterns were obtained on a Siemens D5000 instrument operating at $40 \mathrm{kV}$ and $20 \mathrm{~mA}$, using $\mathrm{CuK} \alpha$ radiation. The morphology of the samples was examined by Scanning Electron Microscopy (SEM) on a Zeiss DSM 942 microscope. Transmission electron micrographs (TEM) were taken on a JEOL (JEM 2100-F) apparatus operating at $200 \mathrm{kV}$. The nitrogen sorption isotherms and textural properties of the carbons were determined at $-196{ }^{\circ} \mathrm{C}$ by means of a conventional volumetric technique (Micromeritics ASAP 2020). The surface area was calculated by the BET method from the adsorption data obtained in the relative pressure $\left(\mathrm{p} / \mathrm{p}_{\mathrm{o}}\right)$ range of 0.01 to 0.1 . The total pore volume was determined from the amount of nitrogen adsorbed at $\mathrm{p} / \mathrm{p}_{\mathrm{o}}=0.99$. The pore size distribution (PSD) was calculated by means of the Kruk-Jaroniec-Sayari method [18] applied to the adsorption branch. The micropore and mesopore volumes were calculated by the $\alpha_{s}$-plot analysis. The Raman spectra were recorded on a Horiva (LabRam HR-800) spectrometer. The source of radiation was a laser operating at a wavelength of $514 \mathrm{~nm}$ and a power of $25 \mathrm{~mW}$. Thermogravimetric analysis of the carbon samples was carried out in a CI Electronics system. The electrical conductivity of the carbon materials was determined by pressing the sample between two plungers into a hollow Nylon cylinder (inner diameter of 8 $\mathrm{mm}$ ), and applying a pressure of up to $7.1 \mathrm{MPa}$. 


\subsection{Electrochemical tests}

The electrochemical measurements were performed in a two-electrode Swagelok ${ }^{\mathrm{TM}}$ type cell. The electrodes were prepared by mixing $90 \mathrm{wt} \%$ of active material (i.e. graphitic carbon) with 10 wt.\% of polytetrafluoroethylene (PTFE) binder (Aldrich, 60\% suspension in water). The two electrodes, of comparable mass, were electrically isolated by glassy fibrous separator. Stainless steel rods were used as current collectors. The cell was built in a dry-box under argon, using as organic electrolyte a solution of $1 \mathrm{M}$ tetraetylamonium tetrafluoroborate $\left(\mathrm{Et}_{4} \mathrm{NBF}_{4}\right)$ (Aldrich) in acetonitrile (AC). Electrochemical characterization was performed using a computer controlled potentiostat (Biologic VMP3 multichannel potentiostat). Cyclic voltammetry was conducted between 0 and $2 \mathrm{~V}$ at sweep rates ranging from 1 to $100 \mathrm{mV} \cdot \mathrm{s}^{-1}$. The gravimetric capacitance, $\mathrm{C}\left(\mathrm{F} \cdot \mathrm{g}^{-1}\right)$, was calculated by means of the formula:

$$
\mathrm{C}=\frac{2 \mathrm{I}}{(\mathrm{dV} / \mathrm{dt}) \cdot \mathrm{m}}
$$

where $\mathrm{I}=$ current $(\mathrm{A}), \mathrm{dV} / \mathrm{dt}=$ scan rate $\left(\mathrm{V} \cdot \mathrm{s}^{-1}\right)$ and $\mathrm{m}=$ mass $($ grams $)$ of carbon in each electrode.

Galvanostactic charge/discharge cycling was also performed in the $0-2 \mathrm{~V}$ range, at current densities in the $0.05-20 \mathrm{~A} \cdot \mathrm{g}^{-1}$ range, based on the active mass of a single electrode. The gravimetric capacitance, $\mathrm{C}\left(\mathrm{F} \cdot \mathrm{g}^{-1}\right)$, was calculated by means of the formula:

$$
\mathrm{C}=\frac{2 \mathrm{I}}{(\mathrm{dV} / \mathrm{dt}) \cdot \mathrm{m}}
$$

where $\mathrm{I}=$ current $(\mathrm{A}), \mathrm{dV} / \mathrm{dt}=$ slope of the discharge curve $\left(\mathrm{V} \cdot \mathrm{s}^{-1}\right)$ and $\mathrm{m}=$ mass (grams) of carbon in each electrode. 


\section{Results and discussion}

\subsection{Monolithic porous carbon from RF-tetraethylenepentamine}

The condensation of phenolic derivatives (i.e. resorcinol) with formaldehyde in the presence of primary amines (Mannich reaction) gives rise to benzoxazine monomers, which can be easily polymerized to polybenzoxazine by simple thermal treatment. This material is a thermosetting polymer that exhibits the following important advantages over the conventional phenolic resins: a) no catalysts are required for curing, b) near zero volumetric changes upon curing, c) release of non-toxic byproducts during curing, etc [19-21]. In addition, such materials have high carbon yields, which make them excellent precursors for the synthesis of a variety of carbon materials [22]. Recently, Lu et al. have demonstrated that by varying the concentration of the reactants used in the synthesis, it is possible to modulate the morphology of polybenzoxazine from nanospheres (dilute conditions) [23] to monoliths (highconcentration conditions) [16]. Both morphologies can be easily transferred to carbon through a carbonization step. In the present work, we have adopted this strategy and used high-concentration conditions to fabricate porous graphitic carbon monoliths. To produce the benzoxazine monomers, tetraethylenepentamine (TEPA) was used as primary amine. $\mathrm{Lu}$ et al. demonstrated that mesostructured carbon-based polybenzoxazine monoliths can be synthesized by using simple protic amines (i. e. dimethylamine, ethylenediamine or 1,6-diaminohexane) but not by aprotic bases such as trimethylamine [16]. In the present work we extend this concept to more complex protic organic bases such as TEPA and demonstrated that they are also suitable to produce this type of mesostructured materials. In this respect, we analyzed the use of other polyamines (i. e. $\quad$ bis(3-aminopropyl)amine, tris(2-aminoethyl)amine, pentaethylenehexamine and polyethylenimine-ethylenediamine branched) and observed 
that they are also appropriate to this end (data not shown). The use of these types of amines strongly affects the characteristics of the carbonized products. Indeed, their large nitrogen content gives rise to N-rich mesostructured carbons which are important for several emergent applications (i. e. metal-free electrocatalysts for oxygen reduction). Moreover, the employ of a polyamine such as TEPA instead of more simple amines $(i$. e. 1,6-daminohexane) induces changes in the carbon mesostructure, which involve an enlargement of the size of mesopores (vide infra).

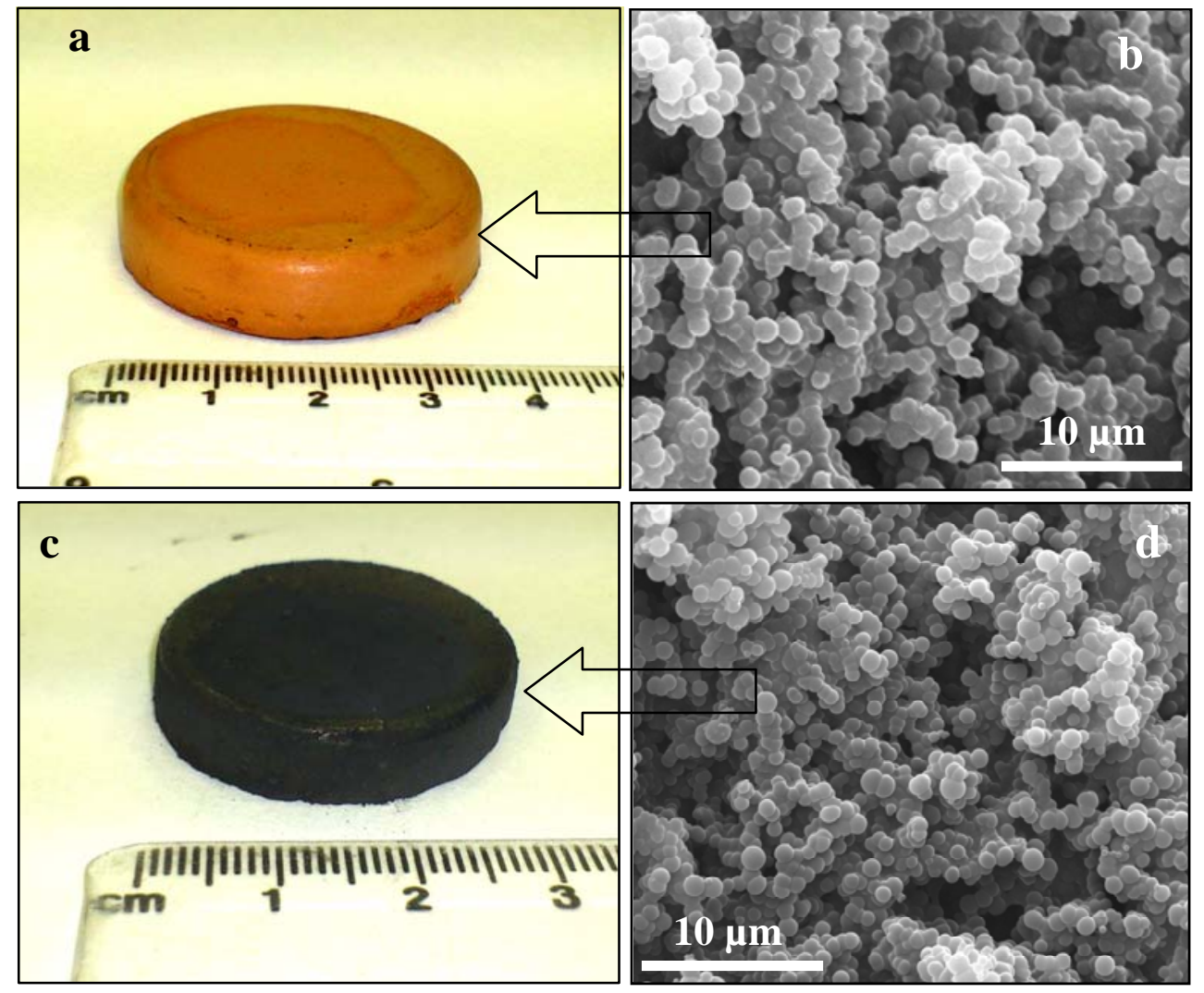

Figure 1. Photographs and SEM images of the polymer $(a, b)$ and carbon monolith CRF-800 (c, d).

Carbonization of the polymer monoliths yields carbon samples that retain the structure and shape of the monolith, as illustrated by Figures 1a and 1c. A comparison of the photographs of the polymer and carbon monoliths shows that a large shrinkage takes place during the carbonization step, with a reduction in volume of around $63 \%$ 
(diameter: - $21 \%$; height: - $40 \%$ ). In spite of this volumetric contraction, the carbon monolith does not show the formation of any fissure. By thermogravimetric analysis, it was found that the carbon residue remaining after decomposition of the polymer monolith was $\sim 30 \mathrm{wt} \%$ (see Fig. S1a in Supporting Information). Around $60 \%$ of the weight loss occurs at $<400{ }^{\circ} \mathrm{C}$, a large fraction of this corresponding to the decomposition of the surfactant. SEM inspection of the internal structure of the polymer and carbon monoliths revealed that both samples have a similar sponge-like structure made up of large voids and interconnected microspheres of $\sim 1$ micron in diameter (see Figures $1 b$ and $1 d)$.

At a nanometer scale, the carbon monolith CRF-800 has a well-ordered mesoporous structure, as is clearly illustrated by the TEM image in Figure 2a. This is confirmed by the XRD pattern in the low-angle range, which exhibits a pronounced peak (see Fig. 2b). In addition, sample CRF-350 also shows a well-defined XRD peak, which proves that the surfactant has been successfully removed after pyrolysis at $350^{\circ} \mathrm{C}$. The weight loss at this temperature is around $50 \%$, as deduced by TGA (see Figure S1b in Supporting Information).
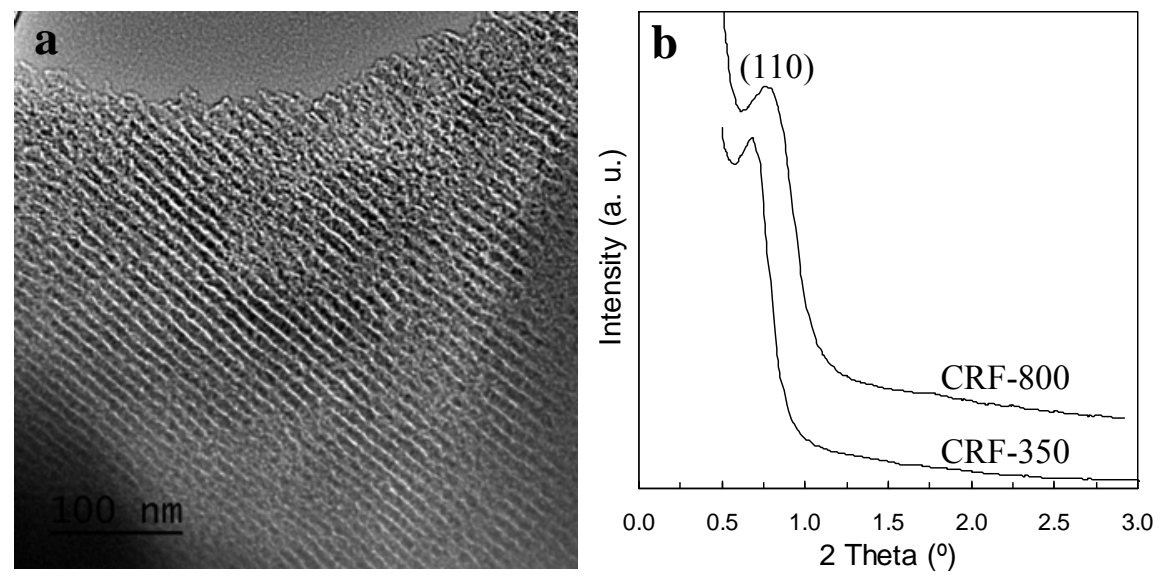

Figure 2. (a) TEM image of CRF-800 in the (110) direction and (b) XRD patterns in the low-angle region. 


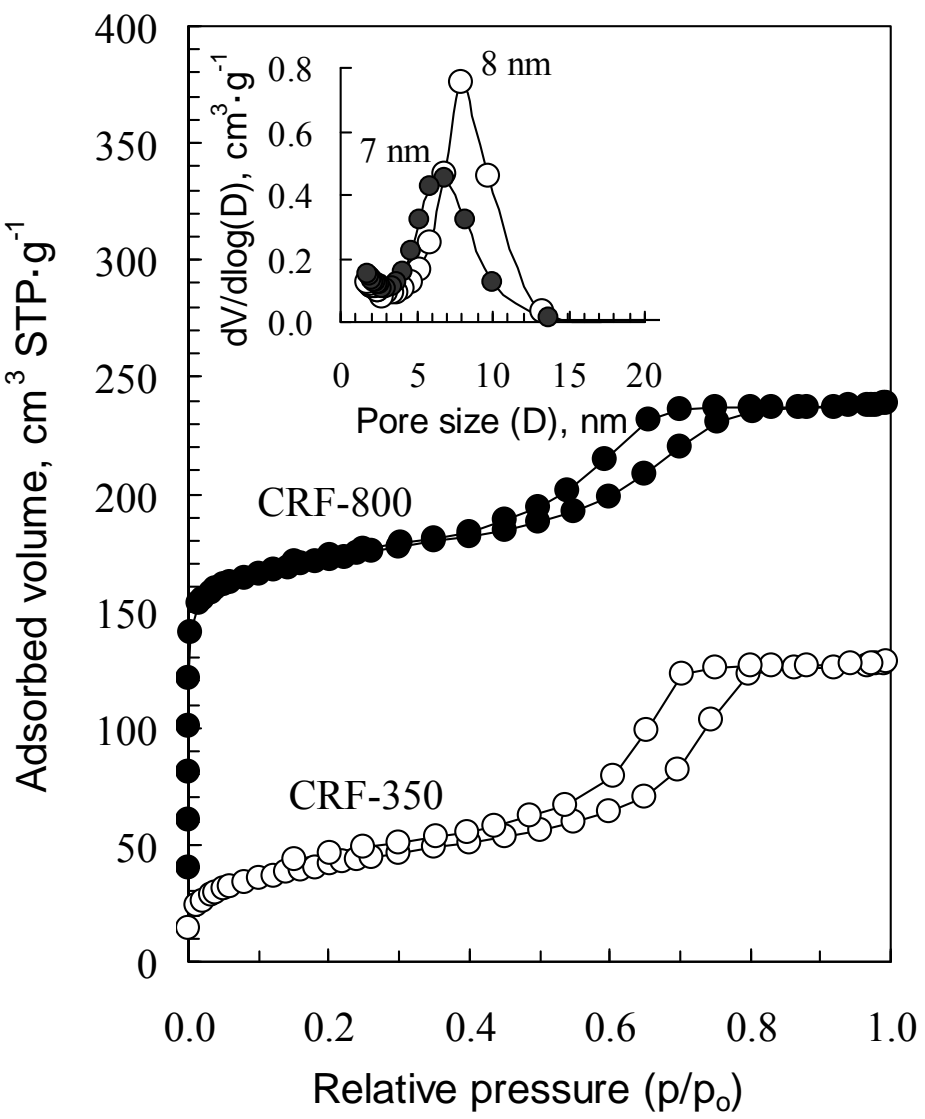

Figure 3. $\mathrm{N}_{2}$ sorption isotherms and pore size distributions (inset) of the CRF-350 (open symbols) and CRF-800 (black symbols) samples.

The nitrogen sorption isotherms and corresponding pore size distributions (PSDs) of the carbonized samples (i. e. CRF-350 and CRF-800) are displayed in Figure 3. The textural properties of these materials are listed in Table 1. The sorption isotherms exhibit a well-defined capillary condensation step at $\mathrm{p} / \mathrm{p}_{\mathrm{o}} \sim 0.6-0.8$, which indicates the presence of uniform mesopores. This is confirmed by the pore size distributions (inset in Fig. 3). Indeed, these samples exhibit PSDs centred at $\sim 8 \mathrm{~nm}$ and $\sim 7 \mathrm{~nm}$ for CRF350 and CRF-800 respectively, their respective BET surface areas being 350 and 590 $\mathrm{m}^{2} \cdot \mathrm{g}^{-1}$. The CRF-800 sample also contains a large number of micropores as is deduced from the $\alpha_{s}$-plot analysis $(\sim 40 \%$ of the pore volume can be assigned to pores of $<2 \mathrm{~nm}$ - see Table 1). By contrast, the porosity of the CRF-350 sample is made up almost 
exclusively of mesopores (see Table 1). The CRF-350 sample has two important characteristics for the fabrication of graphitic monoliths: a) it contains an accessible porosity suitable for being infiltrated by the graphitizing catalyst precursor and b) due to the low heat-treatment temperature, it is not a true carbon but a semi-carbonized product with a large density of highly functionalized graphite-like lamellar molecules, which results very appropriate for graphitization by the catalytic action of inserted metal nanoparticles [24].

Table 1. Textural properties of the carbonized RF monoliths and porous graphitic monoliths.

\begin{tabular}{lllllll}
\hline Sample & $\begin{array}{l}\mathrm{S}_{\mathrm{BET}}, \\
\left(\mathrm{m}^{2} \cdot \mathrm{g}^{-1}\right)\end{array}$ & $\begin{array}{l}\mathrm{V}_{\mathrm{p}} \\
\left(\mathrm{cm}^{3} \cdot \mathrm{g}^{-1}\right)\end{array}$ & $\begin{array}{l}\text { Pore } \\
(\mathrm{nm})\end{array}$ & size & \multicolumn{3}{c}{$\alpha_{\mathrm{s}}$-plot analysis } \\
\cline { 6 - 7 } & 350 & 0.20 & 8 & 0.01 & 0.18 & 0.01 \\
CRF-350 & 350 & & $\mathrm{~V}_{\mathrm{o}}\left(\mathrm{cm}^{3} \cdot \mathrm{g}^{-1}\right)^{\mathrm{a}}$ & $\mathrm{V}_{\mathrm{m}}{ }^{\mathrm{I}}\left(\mathrm{cm}^{3} \cdot \mathrm{g}^{-1}\right)^{\mathrm{b}}$ & $\mathrm{V}_{\mathrm{m}}{ }^{\mathrm{II}}\left(\mathrm{cm}^{3} \cdot \mathrm{g}^{-1}\right)^{\mathrm{c}}$ \\
CRF-800 & 592 & 0.37 & 6.9 & 0.16 & 0.20 & 0.01 \\
PGM-Fe-800 & 407 & 0.39 & $2.5-10$ & 0.07 & 0.24 & 0.08 \\
PGM-Ni-800 & 291 & 0.35 & $2.5-10$ & 0.04 & 0.09 & 0.22 \\
PGM-Co-800 & 423 & 0.37 & $2.4-8$ & 0.07 & 0.24 & 0.06 \\
PGM-Co-D-800 & 425 & 0.43 & $2.4-8$ & 0.05 & 0.29 & 0.09 \\
\hline
\end{tabular}

${ }^{a}$ Micropore volume; ${ }^{b}$ Mesopore volume; ${ }^{c}$ Pore volume of the macropores and large mesopores.

\subsection{Monolithic porous carbon with a graphitic framework}

For the fabrication of graphitic monoliths, the CRF-350 sample was used as starting material. First, it was impregnated with nitrates of different transition metals ( $\mathrm{Fe}, \mathrm{Co}$ or $\mathrm{Ni}$, which have already been demonstrated to be effective graphitization catalysts [2426]. The impregnated sample was then subjected to heat treatment under an inert atmosphere. In this step, the deposited metal nitrates first decompose to their corresponding metal oxides (e.g. $\sim 300^{\circ} \mathrm{C}$ for nickel nitrate). Subsequently, at higher temperatures, these oxides are reduced by carbon (the so-called carbothermal reduction) to metal nanoparticles (e.g. at $\sim 400^{\circ} \mathrm{C}$ the formation of $\mathrm{Ni}$ nanoparticles commences) 
[27]. Finally, at temperatures above $700{ }^{\circ} \mathrm{C}$, the conversion of amorphous carbon into more ordered carbon begins through the catalytic action of the metal nanoparticles contained within the carbon matrix. This process occurs following a dissolutionprecipitation mechanism, whereby amorphous carbon first dissolves into the metal catalyst, and then precipitates from the nanoparticles as graphitic carbon [28]. The TEM image in Figure 4a representing the graphitized sample PGM-Ni-1000 reveals three different phases: a) nickel nanoparticles, b) amorphous carbon and c) graphitic nanostructures. Once the metal nanoparticles have been removed by acid washing, the resulting materials are a mixture of amorphous and graphitic carbon as clearly illustrated in Figure 4b. The graphitic carbon nanostructures are made up of curved nanoribbons formed around the metal nanoparticles through the catalytic graphitization process (see Figure 4a). These nanoribbons have a high crystallinity, as is demonstrated by the HR-TEM image in Figure 4c, which displays very well-defined (002) lattice fringes, and also by the selected area electron diffraction pattern, shown as inset in Figure 4c. At a macroscopic level, the graphitic monolith retains the shape of the polymeric precursor (see Figure $4 \mathrm{~d} /$ inset). In addition, it exhibits a large shrinkage similar to that detected for the CRF-800 sample. It is especially worth mentioning that, in spite of the large shrinkage that occurs during the carbonization-graphitization process, the surface of the graphitic monolith does not exhibit any cracks. The SEM image in Figure $4 \mathrm{c}$ reveals that the graphitized monolith has a fully interconnected sponge-like structure with large voids, analogous to that observed in the polymeric and carbonized monoliths. However, in this case, the basic unit consists of melted irregular microparticles instead of the microspheres observed in the carbonized monolith CRF800. 

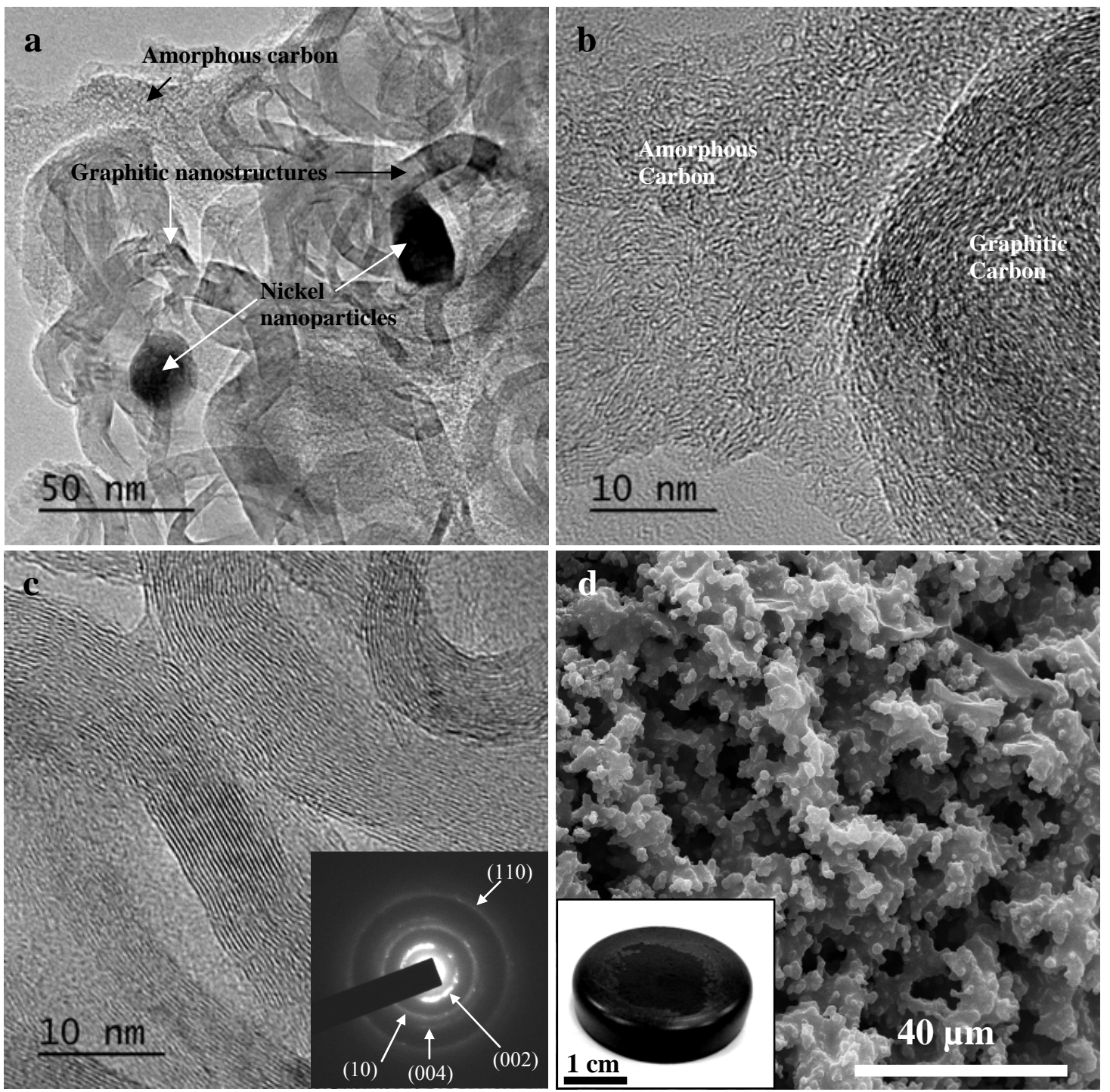

Figure 4. TEM images of the PGM-Ni-1000 sample: (a) before and (b, c) after acid washing (Inset: selected area electron diffraction pattern of the graphitic nanoribbons). (d) SEM image of PGM-Ni-800 (inset: photograph of a graphitic monolith).

The graphitic nature of the monoliths was further examined by thermogravimetric analysis, XRD and Raman spectroscopy. Figure 5 displays the weight loss (Fig. 5a) and weight loss rate (Fig. 5b) curves obtained for the nongraphitized and graphitized samples heat-treated in air. As shown in Figure 5a, the oxidation of the CRF-800 sample (amorphous carbon) occurs in only one step, the maximum of the weight loss rate occurring at $\sim 500{ }^{\circ} \mathrm{C}$ (see Figure $5 \mathrm{~b}$ ). By contrast, the 
oxidation curves for the graphitized samples clearly exhibit two steps, the maxima of the weight loss rate curves occurring at $\sim 500^{\circ} \mathrm{C}$ and $\sim 600{ }^{\circ} \mathrm{C}$. As illustrated in Figure $5 \mathrm{~b}$, these peaks can be ascribed to the amorphous and graphitic phases respectively. If we take into account the difference in the oxidation rates for both carbon phases, we can quantify the amount of graphitic carbon present in the graphitized samples. This amount corresponding to the samples obtained at $800{ }^{\circ} \mathrm{C}$ varies from $40 \mathrm{wt} \%$ (PGM-Co-800) to 66 wt \% (PGM-Fe-800) (see Table 2). Interestingly, in the case of the samples prepared with $\mathrm{Ni}$ as catalyst, we observed an increase in the amount of graphitic carbon as the temperature varied from $800{ }^{\circ} \mathrm{C}(62 \mathrm{wt} \%)$ to $1000{ }^{\circ} \mathrm{C}(77 \mathrm{wt} \%)$ (see Figure 5a).
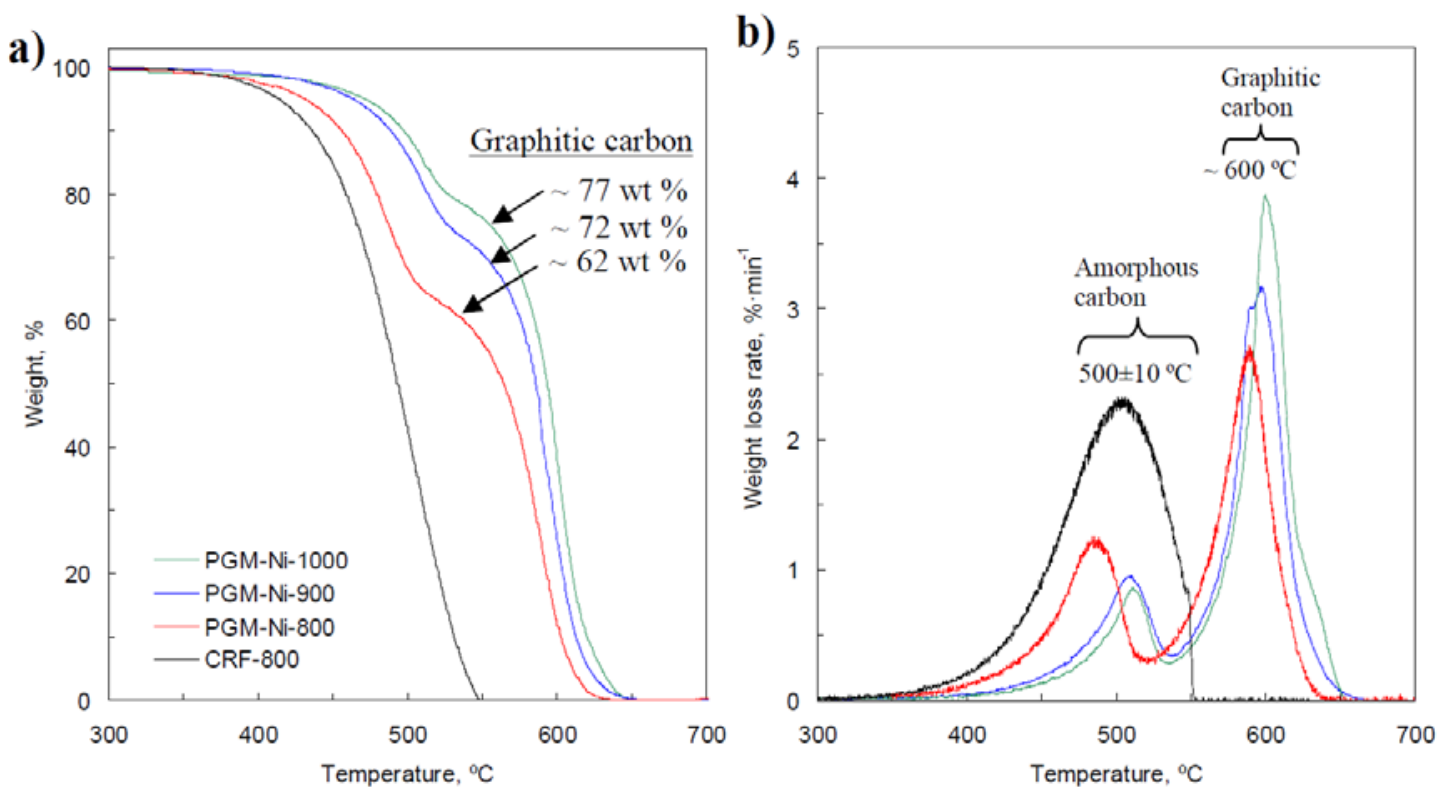

Figure 5. Thermogravimetric curves for the carbon monoliths in an air flow: a) weight loss and b) weight loss rate. The heating rate was $2^{\circ} \mathrm{C} \cdot \mathrm{min}^{-1}$. 
Table 2. Properties of porous graphitic carbon monoliths.

\begin{tabular}{lcllll}
\hline Sample & $\begin{array}{l}\text { Graphitic carbon } \\
(\mathrm{wt} \%)^{\mathrm{a}}\end{array}$ & $\begin{array}{l}d_{002} \\
(\mathrm{~nm})\end{array}$ & $\begin{array}{l}L_{c} \\
(\mathrm{~nm})\end{array}$ & $\begin{array}{l}\text { Conductivity } \\
\left({\left.\mathrm{S} \cdot \mathrm{cm}^{-1}\right)}^{\mathrm{b}}\right.\end{array}$ & $\begin{array}{l}\text { N content } \\
(\mathrm{wt} \%)\end{array}$ \\
\hline CRF-800 & 0 & $\sim 0.38$ & $<2$ & 1.5 & 0.98 \\
PGM-Fe-800 & $\sim 66$ & 0.342 & 4.6 & 2.4 & 0.71 \\
PGM-Ni-800 & $\sim 62$ & 0.341 & 9.0 & 6.4 & 0.86 \\
PGM-Co-800 & $\sim 40$ & 0.343 & 5.4 & 3.7 & 0.53 \\
PGM-Co-D-800 & $\sim 50$ & 0.343 & 6.4 & 4.9 & 0.43 \\
\hline
\end{tabular}

${ }^{a}$ Determined by means of thermogravimetric analysis; ${ }^{\mathrm{b}}$ electronic conductivity measured by pressing a powdered sample at 7.1 MPa.

The XRD patterns in the wide-angle region $\left(20^{\circ}-90^{\circ}\right)$ corresponding to the samples synthesized at $800^{\circ} \mathrm{C}$ are shown in Figure 6a. These graphitized materials exhibit XRD peaks at $2 \theta \approx 26^{\circ}, 43^{\circ}, 54^{\circ}$ and $78^{\circ}$, which can be assigned to the (002), (10), (004) and (110) diffractions of the graphitic framework, respectively. Table 2 contains the structural parameters deduced from these XRD patterns, i.e. (002) plane spacing $\left(d_{002}\right)$ and the crystallite size perpendicular to the basal plane $\left(L_{c}\right)$. The values of $d_{002}$ are around $0.34 \mathrm{~nm}$. Thus, they are larger than that of graphite $(0.335 \mathrm{~nm})$, suggesting a random combination of graphitic and turbostratic stacking [29]. The values obtained for $L_{c}$ are in the $5-9 \mathrm{~nm}$ range. This parameter depends mainly on the type of metal used as catalyst for graphitization. Thus, the samples obtained in the presence of Ni show, with respect to those obtained with Co or Fe, larger $L_{c}$ values, indicating that $\mathrm{Ni}$ is a better catalyst for heterogeneous graphitization. Figure $6 \mathrm{~b}$ shows the Raman spectra obtained in two different regions of the PGM-Co-D-800 sample. One of them (lower) has a strong G-band at $1572 \mathrm{~cm}^{-1}$ and a weak D-band at $1350 \mathrm{~cm}^{-1}$, which clearly indicates the presence of graphitic structures $\left(\mathrm{I}_{\mathrm{D}} / \mathrm{I}_{\mathrm{G}}=0.28\right)$. The other spectrum (upper) contains two broad bands, as might be expected for a disordered carbon $\left(\mathrm{I}_{\mathrm{D}} / \mathrm{I}_{\mathrm{G}}=0.90\right)$. This result clearly confirms that the carbon framework in the graphitized monoliths consists of a heterogeneous mixture of amorphous and graphitic carbon. 
Table 2 shows the electronic conductivities of the samples prepared at $800{ }^{\circ} \mathrm{C}$. As expected, the graphitization step induces a considerable enhancement in electronic conductivity and, in consequence, the graphitic monoliths exhibit higher conductivities than the non-graphitized CRF-800 sample. These values uniformly increase with the crystallite size perpendicular to the basal plane $\left(L_{c}\right)$ as illustrated in Figure S2 (Supporting Information). Accordingly, the best conductivity $\left(6.4 \mathrm{~S} \cdot \mathrm{cm}^{-1}\right)$ corresponds to the sample (PGM-Ni-800) which has the largest $L_{c}(9 \mathrm{~nm})$. Elemental analysis shows that these graphitized monoliths have a nitrogen content that is derived from the TEPA polyamine used in the synthesis. These contents are in the $0.4-1 \mathrm{wt} \%$ range (see Table 2). N-doped carbons have recently generated a great deal of interest because they have proved to be effective catalysts for the oxygen reduction reaction (fuel cell cathodic reaction), which normally requires supported expensive noble metal catalyst such as $\mathrm{Pt}$ and $\mathrm{Ru}[30]$. In addition, the $\mathrm{N}$-doped carbons have enhanced capacitance when used in supercapacitors due to their increased electrical conductivity and to pseudocapacitance phenomena $[31,32]$. 
a)

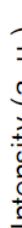

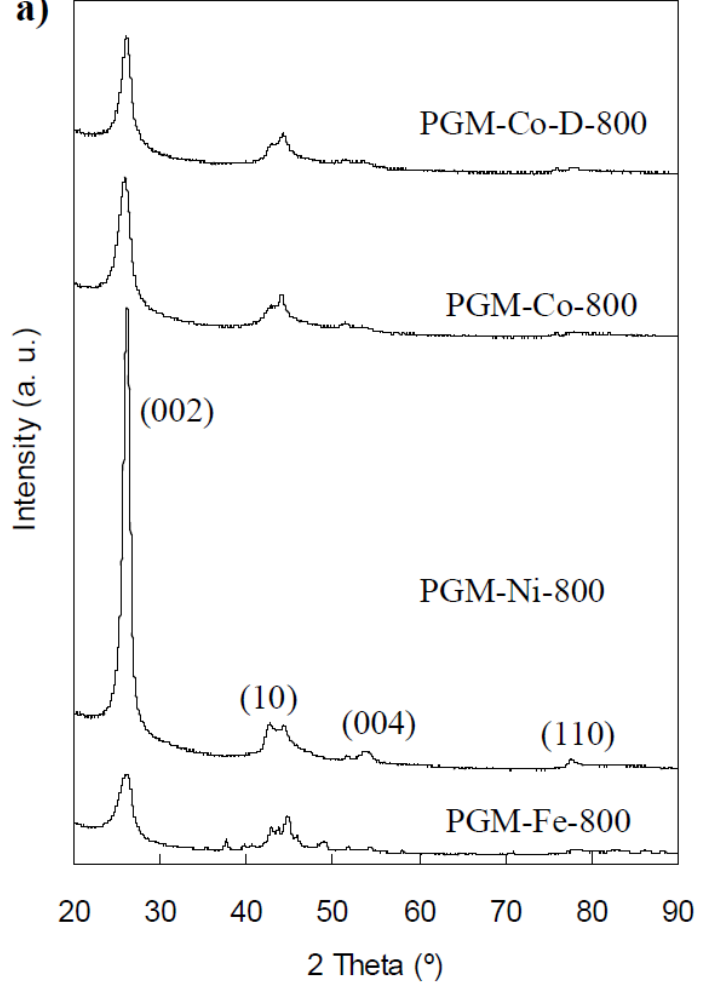

b)

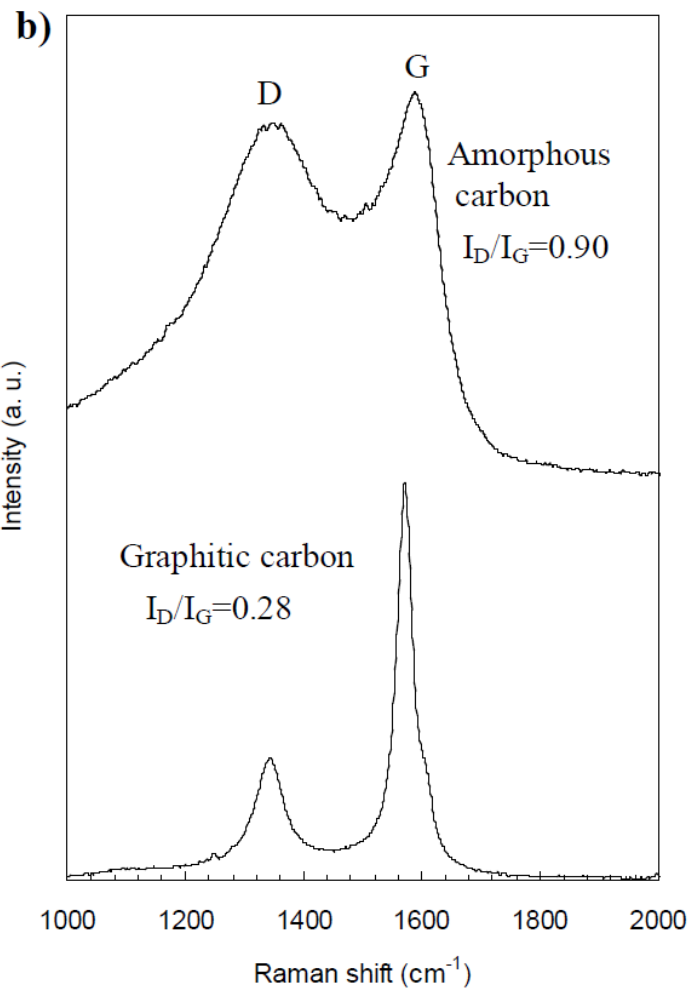

Figure 6. (a) XRD patterns and (b) Raman spectra of graphitic and amorphous carbon domains in the PGM-Co-D-800 sample.
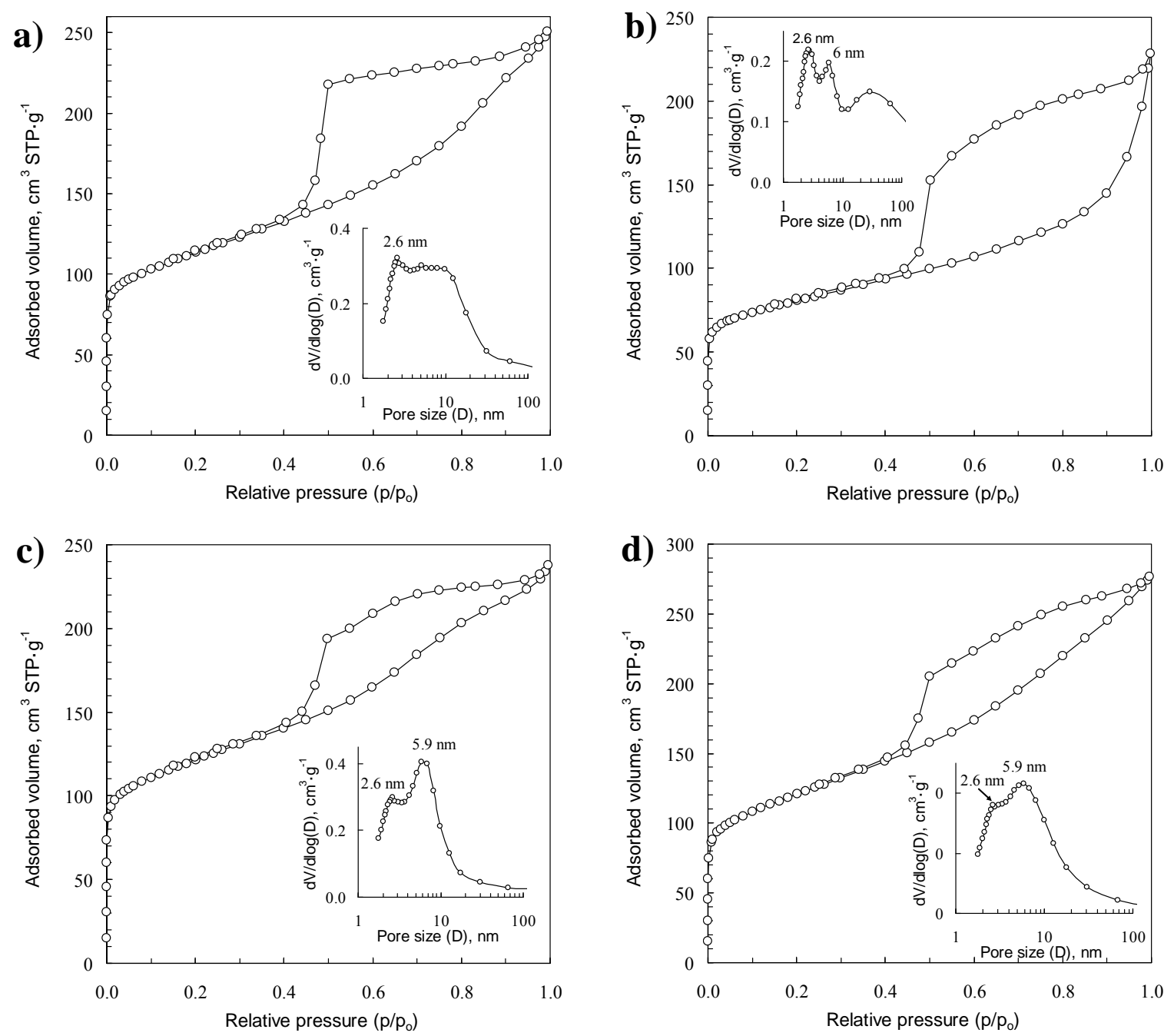
Figure 7. Nitrogen sorption isotherms and the corresponding PSD curves (insets) of the mesoporous graphitic carbon monoliths: (a) PGM-Fe-800, (b) PGM-Ni-800, (c) PGMCo-800 and (d) PGM-Co-D-800.

The nitrogen sorption isotherms and pore size distributions corresponding to the graphitized monoliths are depicted in Figure 7. The BET surface area, pore volume and pore size of the graphitized carbons are summarized in Table 1. The surface area of these samples are in the $280-395 \mathrm{~m}^{2} \cdot \mathrm{g}^{-1}$ range, which are lower than those of CRF-800 $\left(592 \mathrm{~m}^{2} \cdot \mathrm{g}^{-1}\right)$ because graphitization prevents the formation of micropores. Indeed, the results shown in Figure 7 and those deduced by applying the $\alpha_{s}$-plot analysis to the nitrogen isotherms (see Table 1) indicate that the porosity of these materials is essentially made up of mesopores and macropores, there being almost no microporosity at all. The mesopores in the graphitized samples exhibit a wide PSD, in the 2-10 nm range, as shown in Figure 7 (insets). The $\mathrm{N}_{2}$ sorption isotherms exhibit a type- $\mathrm{H} 2$ hysteresis loop with a pronounced desorption step. This is indicative of delayed capillary evaporation and the presence of constrictions in the mesoporous structure (cage-like pores). At this point, it should be mentioned that the graphitic carbon generated during the carbonization step is formed around the metal nanoparticles that act as catalyst. The removal of these metallic nanoparticles gives rise to hollow graphitic carbon nanostructures such as capsules with entrances and other carbon structures with large voids (i. e. nanotubules). The constrictions associated to the entrances of these nanostructures are the cause of the observed delayed desorption [24].

We were particularly interested in comparing the properties of graphitic monoliths prepared with Co as catalyst and following the two synthesis strategies described in the experimental section: a) impregnation of the pre-carbonized CRF-350 monolith with a Co compound (i.e. PGM-Co-800 sample) and b) introduction of a Co 
compound into the synthesis mixture (i.e. PGM-Co-D-800 sample). Procedure (b) is much simpler because the pre-carbonization at $350{ }^{\circ} \mathrm{C}$ and impregnation steps are circumvented. A comparison of the physical properties (i.e. graphitic carbon content, electronic conductivity, $\mathrm{N}$ content, $L_{c}$ value, BET surface area, etc.) of both types of sample reveals that they have similar structural and textural properties (see Tables 1 and 2). These results show that the simple procedure used for PGM-Co-D-800 constitutes a useful and easy route to graphitic monoliths. Accordingly, we applied this procedure to iron and nickel, but in both cases we observed that the metal nitrates are unevenly distributed throughout the polymer monolith preventing the formation of homogeneous graphitic monoliths.

\subsection{Electrochemical performance. Supercapacitors}

The synthesized graphitic materials were tested as supercapacitor electrodes in organic electrolyte due to the following advantageous features of these materials: i) an open and easily accessible porosity for the rapid diffusion of organic ions, and ii) a relatively high electronic conductivity, allowing the use of a conductive additive to be avoided; the electrodes were thus composed exclusively of binder and active material. The square shape of the cyclic voltammograms in Figure 8, even at sweep rates of up to $100 \mathrm{mV} \mathrm{s}^{-1}$ (Figure 8b), proves good charge propagation in these materials, which is the result of their accessible porous structure and good electronic conductivity. Indeed, $70-$ $77 \%$ of the gravimetric capacitance is retained when the scan rate is increased from 1 to $100 \mathrm{mV} \mathrm{s}^{-1}$. 

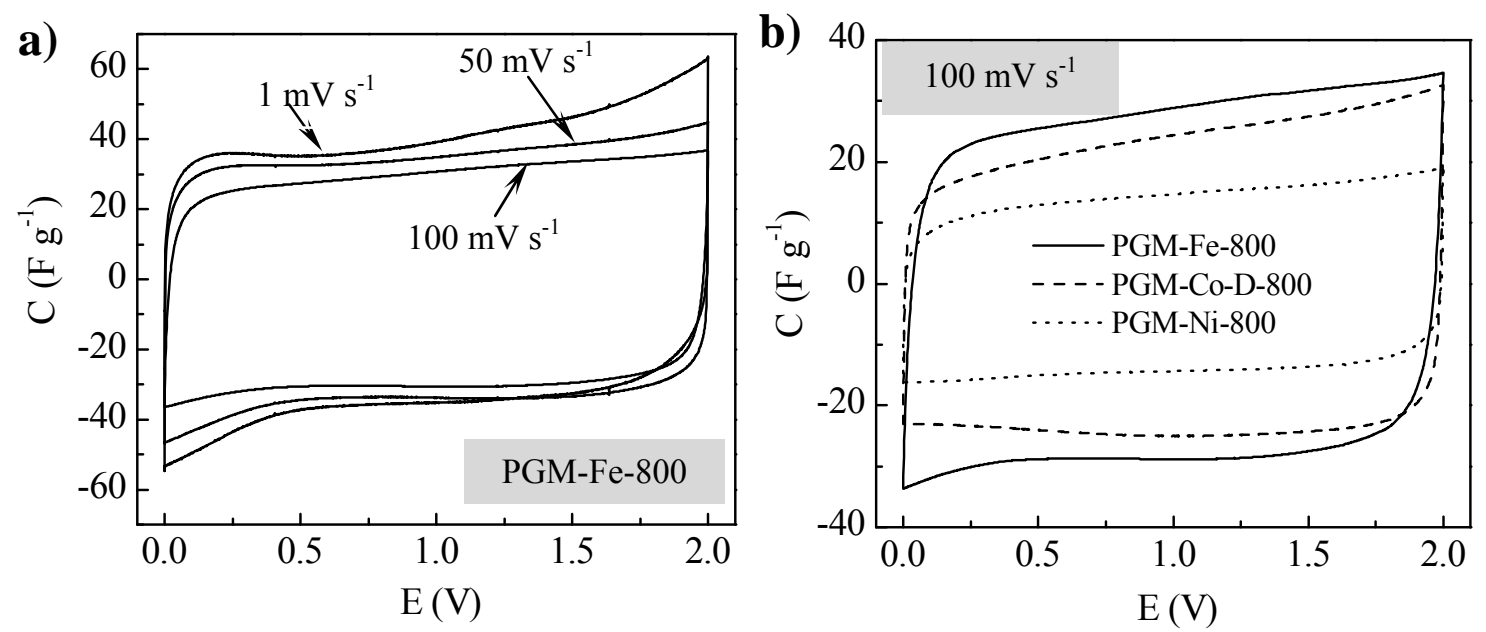

Figure 8. Cyclic voltammograms at room temperature in a solution $1 \mathrm{MTEABF} / \mathrm{AC}$ : a) at different scan rates for PGM-Fe-800 and b) at $100 \mathrm{mV} \cdot \mathrm{s}^{-1}$ for different graphitized samples.

To confirm the good rate performance of these materials, galvanostatic charge/discharge cycling was performed in the voltage range of $0-2 \mathrm{~V}$ at different current densities up to $20 \mathrm{~A} \cdot \mathrm{g}^{-1}$. Figure 9a shows almost no IR drop for low current densities and only a small drop $(0.22-0.45 \mathrm{~V})$ for high currents, the highest IR drop being registered for the sample with the lowest electronic conductivity and the highest micropore volume, i.e. PGM-Fe-800. All the samples exhibit a good capacitance

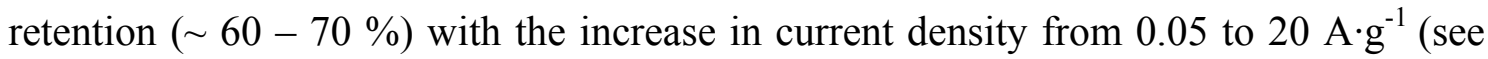
Figure 9b). The gravimetric capacitance normalized per surface area of these materials is in the $0.062-0.086 \mathrm{~F} \cdot \mathrm{m}^{-2}$ range, in line with the values of other mesoporous carbons [33-35] or carbon nanotubes [36]. It should be noted that the material with the highest specific capacitance per surface area is the one with the highest proportion of microporosity (18\%), i.e. PGM-Fe-800. This result is in agreement with studies that show an anomalous increase in capacitance in pores close to the size of the ions due to the distorsion and partial desolvation of the ions [35]. 

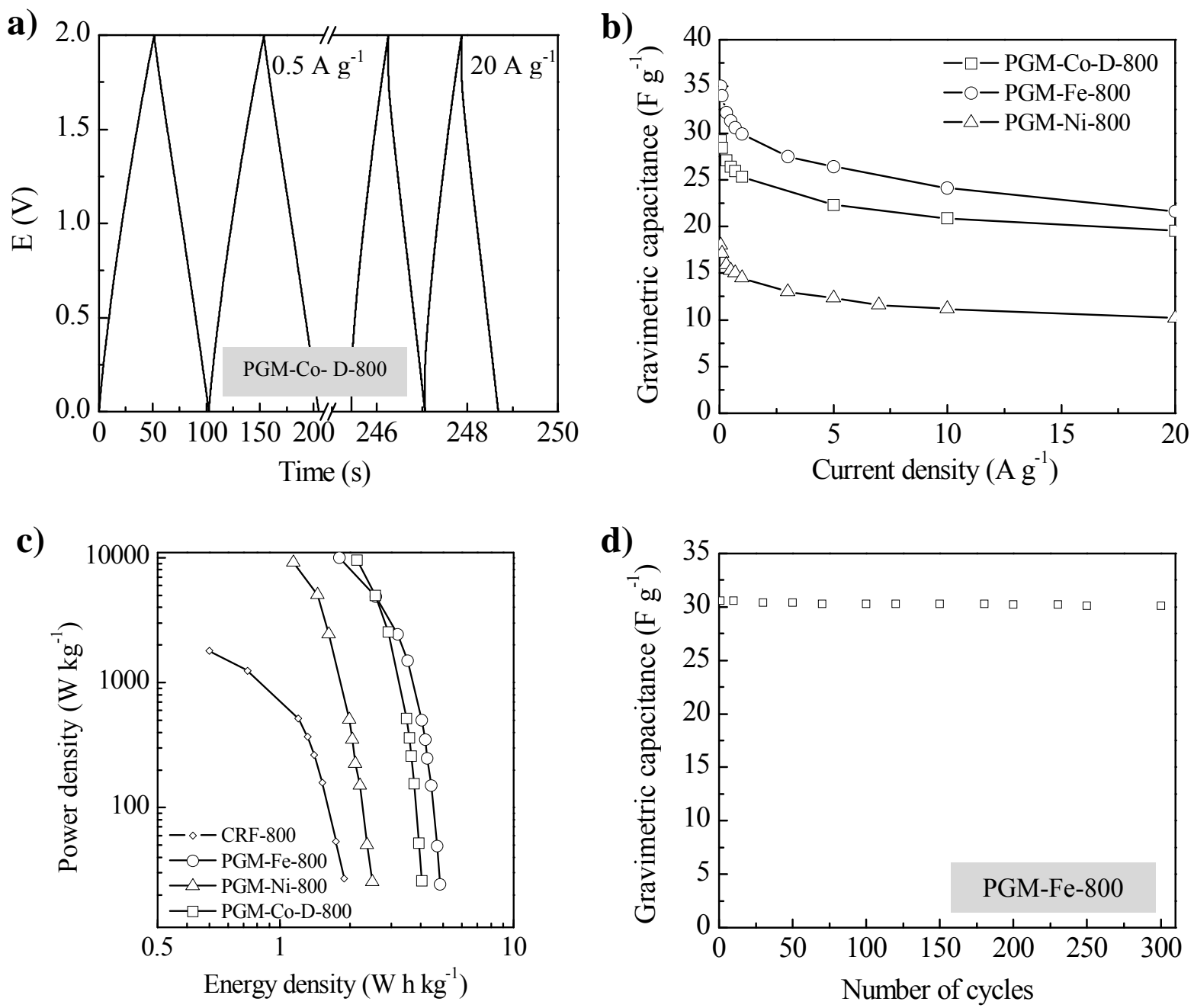

Figure 9. Electrochemical performance of the graphitized samples at room temperature in a solution of $1 \mathrm{M} \mathrm{TEABF}_{4} / \mathrm{AC}$ : a) galvanostatic charge/discharge cycling at 0.5 and $20 \mathrm{~A} \mathrm{~g}^{-1}$ for PGM-Co-D-800, b) specific capacitance retention with current density for the different graphitized samples, c) Ragone plot and d) cycling performance of PGMFe-800 at a current density of $0.7 \mathrm{~A} \cdot \mathrm{g}^{-1}$.

Similarly to carbon nanotubes, the limited surface area of the materials here synthesised restricts their use as high energy performance EDLCs. This is clear from the Ragone plot (Figure 9c), where energy densities no larger than to $2.5-5 \mathrm{~W} \cdot \mathrm{h} \cdot \mathrm{kg}^{-1}$ are achieved, whereas energy densities above $10 \mathrm{~W} \cdot \mathrm{h} \cdot \mathrm{kg}^{-1}$ are normally reachable with mesoporous carbons in this type of electrolyte $[33,34]$. However, these materials stand out for their high power densities up to $10 \mathrm{~kW} \cdot \mathrm{kg}^{-1}$ (energy density of $1.2-2.2 \mathrm{~W} \cdot \mathrm{h} \cdot \mathrm{kg}^{-}$ $\left.{ }^{1}\right)$. The good capacitance retention of these materials combined with the low IR drop 
results in a lower trade-off in the Ragone plot with the increase in the current density, especially in the case of the samples with higher conductivities, i.e. PGM-Ni-800 and PGM-Co-D-800 (see Figure 9c). The superior performance of those graphitized materials compared to the amorphous carbon sample CRF-800 is clearly visible in the Ragone plot. In addition, these materials exhibit a good cycling performance, with only a $2 \%$ loss of capacitance after 300 charge/discharge cycles at a current density of 0.7 $A \cdot g^{-1}$ (see Figure 9d).

\section{Conclusions}

In summary, macro/mesoporous carbon monoliths with a graphitic framework have been synthesized by the carbonization of polymeric monoliths of poly(benzoxazine-co-resol). The synthesis procedure employed is based on the catalytic graphitization of polymeric monoliths prepared through the co-polymerization of resorcinol and formaldehyde with a polyamine (i.e. tetraethylenepentamine), using Fe, Ni or Co as catalyst. The resulting carbon monoliths contain a large proportion of graphitic carbon (>50 wt \%) which considerably improves their electrical conductivity (from $1.5 \mathrm{~S} / \mathrm{cm}$ for the carbon monolith up to $6.4 \mathrm{~S} / \mathrm{cm}$ for the Ni-graphitized carbon monolith). Moreover, the use of tetraethylenepentamine in the synthesis allows the Ndoping of the graphitic monoliths. From a textural point of view, these materials are characterized by a dual porosity made up of macropores and mesopores ( $2-10 \mathrm{~nm})$, their BET surface area and pore volume being, respectively, in the $280-400 \mathrm{~m}^{2} \cdot \mathrm{g}^{-1}$ range and $\sim 0.4 \mathrm{~cm}^{3} \cdot \mathrm{g}^{-1}$. Those materials were tested as supercapacitor electrodes in organic electrolyte (1 M TEABF 4 /AC), recording specific capacitances of up to $35 \mathrm{~F} \cdot \mathrm{g}^{-1}$, a value typical of graphitized nanocarbons, such as carbon nanotubes. Furthermore, they showed an excellent rate and cycling performance, delivering up to $10 \mathrm{~kW} \cdot \mathrm{kg}^{-1}$ at high 
current densities. It is important to note that no conductive additive was needed for the preparation of the electrodes due to their high electrical conductivity.

\section{Acknowledgements}

The financial support for this research work provided by the Spanish MCyT (CQT2011-24776 and MAT2012-31651) is gratefully acknowledged. M. S. thanks the Spanish MCyT for the award of a Ramón y Cajal contract.

\section{References}

[1] Mysyk R, Gao Q, Raymundo-Piñero E, Béguin F. Microporous carbons finelytuned by cyclic high-pressure low-temperature oxidation and their use in electrochemical capacitors. Carbon 2012;50(9):3367-74.

[2] Sevilla M, Valle-Vigon P, Tartaj P, Fuertes AB. Magnetically separable bimodal mesoporous carbons with a large capacity for the immobilization of biomolecules. Carbon 2009;47(10):2519-27.

[3] Sevilla M, Fuertes AB. Sustainable porous carbons with a superior performance for $\mathrm{CO}_{2}$ capture. Energ Environ Sci 2011;4(5):1765-71.

[4] Gogotsi Y, Portet C, Osswald S, Simmons JM, Yildirim T, Laudisio G, et al. Importance of pore size in high-pressure hydrogen storage by porous carbons. Int $\mathrm{J}$ Hydrogen Energ 2009;34(15):6314-9.

[5] Choi M, Jang J. Heavy metal ion adsorption onto polypyrrole-impregnated porous carbon. J Colloid Interf Sci 2008;325(1):287-9.

[6] Zhao J, Cheng F, Yi C, Liang J, Tao Z, Chen J. Facile synthesis of hierarchically porous carbons and their application as a catalyst support for methanol oxidation. $\mathrm{J}$ Mater Chem 2009;19(24):4108-16. 
[7] Ruiz V, Blanco C, Santamaría R, Ramos-Fernández JM, Martínez-Escandell M, Sepúlveda-Escribano A, et al. An activated carbon monolith as an electrode material for supercapacitors. Carbon 2009;47(1):195-200.

[8] Garcia-Gomez A, Miles P, Centeno TA, Rojo JM. Why Carbon Monoliths are Better Supercapacitor Electrodes than Compacted Pellets. Electrochem Solid St 2010;13(8):A112-A4.

[9] Eltmimi AH, Barron L, Rafferty A, Hanrahan JP, Fedyanina O, Nesterenko E, et al. Preparation, characterisation and modification of carbon-based monolithic rods for chromatographic applications. J Sep Sci 2010;33(9):1231-43.

[10] Jungbauer A, Hahn R. Monoliths for fast bioseparation and bioconversion and their applications in biotechnology. J Sep Sci 2004;27(10-11):767-78.

[11] Jaroniec M, Choma J, Gorka J, Zawislak A. Colloidal Silica Templating Synthesis of Carbonaceous Monoliths Assuring Formation of Uniform Spherical Mesopores and Incorporation of Inorganic Nanoparticles. Chem Mater 2007;20(3):1069-75.

[12] Alvarez S, Esquena J, Solans C, Fuertes AB. Meso/Macroporous Carbon Monoliths from Polymeric Foams. Adv Eng Mater 2004;6(11):897-9.

[13] Álvarez García S, Fuertes Arias AB. Synthesis of macro/mesoporous silica and carbon monoliths by using a commercial polyurethane foam as sacrificial template. Mater Lett 2007; 61(11-12): 2378-81.

[14] Liang C, Dai S. Dual Phase Separation for Synthesis of Bimodal Meso/Macroporous Carbon Monoliths. Chem Mater 2009;21(10):2115-24.

[15] Huang Y, Cai H, Feng D, Gu D, Deng Y, Tu B, et al. One-step hydrothermal synthesis of ordered mesostructured carbonaceous monoliths with hierarchical porosities. Chem Commun 2008(23):2641-3. 
[16] Hao G-P, Li W-C, Qian D, Wang G-H, Zhang W-P, Zhang T, et al. Structurally

Designed Synthesis of Mechanically Stable Poly(benzoxazine-co-resol)-Based Porous Carbon Monoliths and Their Application as High-Performance $\mathrm{CO}_{2}$ Capture Sorbents. J Am Chem Soc 2011;133(29):11378-88.

[17] Liang C, Dai S, Guiochon G. A Graphitized-Carbon Monolithic Column. Anal Chem 2003;75(18):4904-12.

[18] Kruk M, Jaroniec M, Sayari A. Application of Large Pore MCM-41 Molecular Sieves To Improve Pore Size Analysis Using Nitrogen Adsorption Measurements. Langmuir 1997;13(23):6267-73.

[19] Allen DJ, Ishida H. Physical and mechanical properties of flexible polybenzoxazine resins: Effect of aliphatic diamine chain length. J Appl Polymer Sci 2006;101(5):2798-809.

[20] Ghosh NN, Kiskan B, Yagci Y. Polybenzoxazines-New high performance thermosetting resins: Synthesis and properties. Prog Polym Sci 2007;32(11):1344-91.

[21] Yagci Y, Kiskan B, Ghosh NN. Recent advancement on polybenzoxazine-A newly developed high performance thermoset. J Polym Sci Pol Chem 2009;47(21):5565-76.

[22] Lorjai P, Chaisuwan T, Wongkasemjit S. Porous structure of polybenzoxazinebased organic aerogel prepared by sol-gel process and their carbon aerogels. J Sol-Gel Sci Technol 2009;52(1):56-64.

[23] Wang S, Li W-C, Hao G-P, Hao Y, Sun Q, Zhang X-Q, et al. TemperatureProgrammed Precise Control over the Sizes of Carbon Nanospheres Based on Benzoxazine Chemistry. J Am Chem Soc 2011;133(39):15304-7.

[24] Sevilla M, Fuertes AB. Catalytic graphitization of templated mesoporous carbons. Carbon 2006;44(3):468-74. 
[25] Oya A, Yoshida S, Alcaniz-Monge J, Linares-Solano A. Formation of mesopores in phenolic resin-derived carbon fiber by catalytic activation using cobalt. Carbon 1995;33(8):1085-90.

[26] Maldonado-Hódar FJ, Moreno-Castilla C, Rivera-Utrilla J, Hanzawa Y, Yamada Y. Catalytic Graphitization of Carbon Aerogels by Transition Metals. Langmuir 2000;16(9):4367-73.

[27] Sevilla M, Fuertes AB. Graphitic carbon nanostructures from cellulose. Chem Phys Lett 2010;490(1-3):63-8.

[28] Ōya A, Marsh H. Phenomena of catalytic graphitization. J Mater Sci 1982;17(2):309-22.

[29] Inagaki M. Chapter 1 - Old but New Materials: “Carbons”. New Carbons Control of Structure and Functions. Oxford: Elsevier Science 2000, p. 1-29.

[30] Su DS, Zhang J, Frank B, Thomas A, Wang X, Paraknowitsch J, et al. MetalFree Heterogeneous Catalysis for Sustainable Chemistry. ChemSusChem. 2010;3(2):169-80.

[31] Hulicova-Jurcakova D, Seredych M, Lu GQ, Bandosz TJ. Combined Effect of Nitrogen- and Oxygen-Containing Functional Groups of Microporous Activated Carbon on its Electrochemical Performance in Supercapacitors. Adv Funct Mater 2009;19(3):438-47.

[32] Seredych M, Hulicova-Jurcakova D, Lu GQ, Bandosz TJ. Surface functional groups of carbons and the effects of their chemical character, density and accessibility to ions on electrochemical performance. Carbon 2008;46(11):1475-88.

[33] Sevilla M, Álvarez S, Centeno TA, Fuertes AB, Stoeckli F. Performance of templated mesoporous carbons in supercapacitors. Electrochim Acta 2007;52(9):320715. 
[34] Fernández JA, Morishita T, Toyoda M, Inagaki M, Stoeckli F, Centeno TA. Performance of mesoporous carbons derived from poly(vinyl alcohol) in electrochemical capacitors. J Power Sources 2008;175(1):675-9.

[35] Chmiola J, Yushin G, Gogotsi Y, Portet C, Simon P, Taberna PL. Anomalous Increase in Carbon Capacitance at Pore Sizes Less Than 1 Nanometer. Science 2006;313(5794):1760-3.

[36] Zhang LL, Zhao XS. Carbon-based materials as supercapacitor electrodes. Chem Soc Rev 2009;38(9):2520-31. 


\section{Supporting Information}
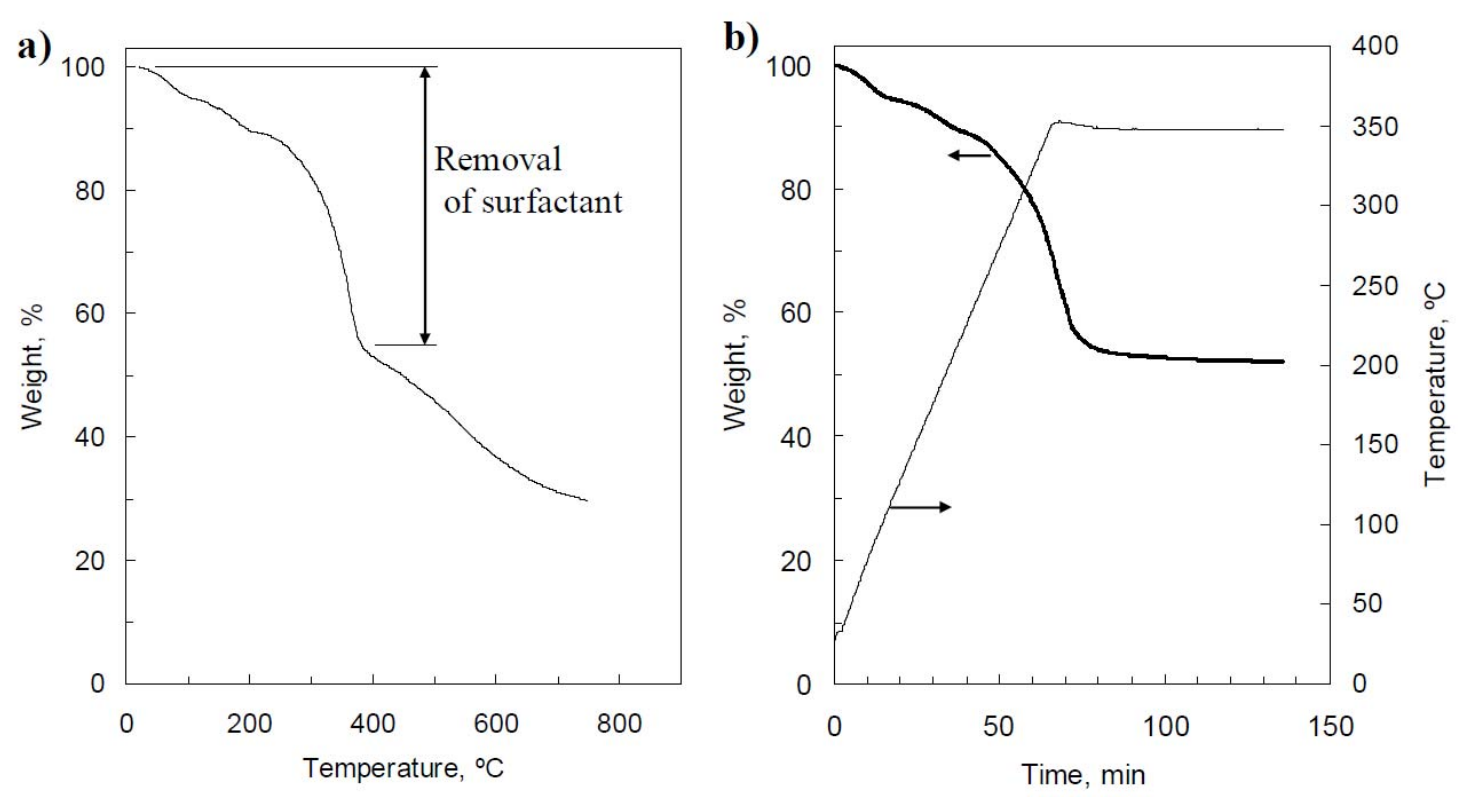

Figure S1. (a) TGA of polymer monolith $\left(\mathrm{N}_{2}, 5^{\circ} \mathrm{C} / \mathrm{min}\right)$, (b) removal of surfactant by heat treatment of as-synthesized RF monolith under nitrogen up to $350{ }^{\circ} \mathrm{C}$.

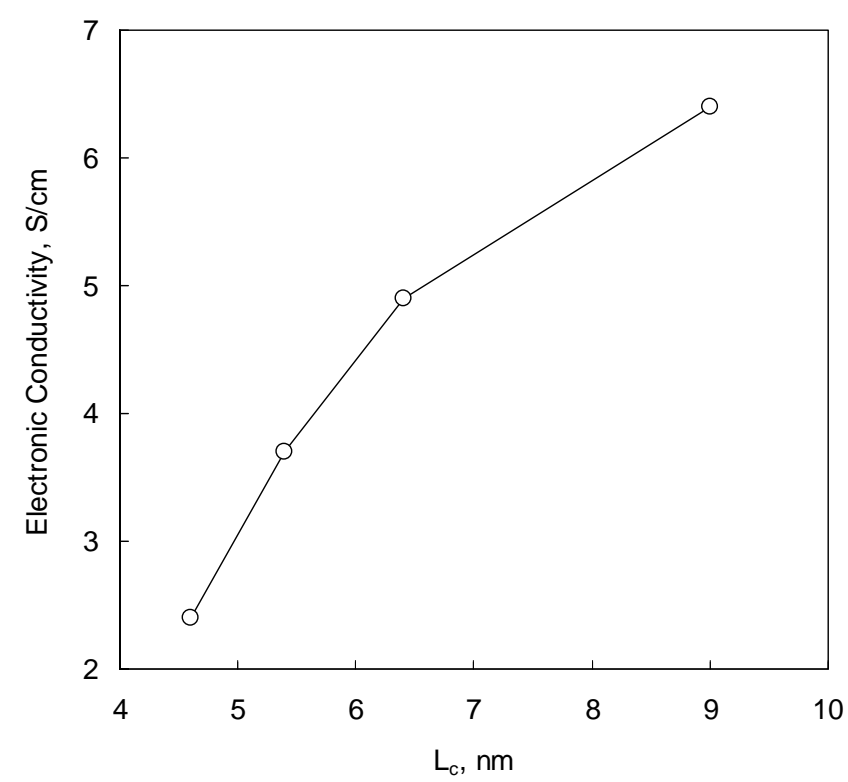

Figure S2. Modification of the electronic conductivity with the $L_{c}$ parameter. 